\title{
Investigation of the 16-year and 18-year ZTD Time Series Derived from GPS Data Processing
}

\author{
Zofia BAŁDYSZ, Grzegorz NYKIEL, Mariusz FIGURSKI, \\ Karolina SZAFRANEK, and Krzysztof KROSZCZYŃSKI \\ Military University of Technology, Faculty of Civil Engineering and Geodesy, \\ Warszawa, Poland; e-mail: zbaldysz@wat.edu.pl
}

\begin{abstract}
The GPS system can play an important role in activities related to the monitoring of climate. Long time series, coherent strategy, and very high quality of tropospheric parameter Zenith Tropospheric Delay (ZTD) estimated on the basis of GPS data analysis allows to investigate its usefulness for climate research as a direct GPS product. This paper presents results of analysis of 16-year time series derived from EUREF Permanent Network (EPN) reprocessing performed by the Military University of Technology. For 58 stations Lomb-Scargle periodograms were performed in order to obtain information about the oscillations in ZTD time series. Seasonal components and linear trend were estimated using Least Square Estimation (LSE) and Mann-Kendall trend test was used to confirm the presence of a linear trend designated by LSE method. In order to verify the impact of the length of time series on trend value, comparison between 16 and 18 years were performed.
\end{abstract}

Key words: GPS, ZTD, time series, troposphere.

\section{INTRODUCTION}

Water vapour is one of the main gases causing greenhouse effect. Because it is responsible for energetic balance of the Earth (Held and Soden 2006), and in $60-70 \%$ for increasing the temperature on the surface of Earth (COST 
2012), water vapour plays a key role in the process of climate monitoring. Besides many techniques which allow to measure water vapour content in the atmosphere (Integrated Water Vapour - IWV), GPS system plays a significant role in this task. Advanced analysis of GPS observations provides tropospheric parameter Zenith Tropospheric Delay (ZTD), which represents the impact of weather conditions (troposphere) on the propagation of satellite signals. ZTD consists of two parts: a delay caused by the hydrostatic part of atmosphere (Zenith Hydrostatic Delay - ZHD), and delay related to the wet part of atmosphere (Zenith Wet Delay - ZWD). ZHD accounts for about $90 \%$ of ZTD, and it is easy to model due to the low variability of this parameter in time. ZWD, which accounts for about $10 \%$ of ZTD, cannot be accurately modeled due to uneven space, temporal, and vertical distribution of water vapour. Because the size of ZTD depends on the state of the troposphere, this parameter shows correlation with changeable-in-time temperature (Guerova 2013) and time-varying content of water vapour (Yong et al. 2008). Using selected meteorological data it also allows to estimate IWV (Bevis et al. 1992, Hagemann et al. 2003, Wang and Zhang 2009) with accuracy at the level of $1-2 \mathrm{~kg} \mathrm{~m}^{-2}$ (Bock et al. 2007, Byun and Bar-Server 2009). Denser than in the case of radiosonde, network of GPS permanent stations which leads measurements with high temporal resolution, enables monitoring of troposphere variability and detecting trends in water vapour content for large areas, simultaneously ensuring proper spatial distribution. Monitoring of long-term changes is crucial in the context of monitoring climate changes. Longstanding global investigations, conducted using for example DORIS technique, show discrepancy in character and size of IWV trend, both in north and south hemisphere (Bock et al. 2014). Analogical situations concerning global trends occur when using GPS system (Ning 2012, Jin et al. 2007). In that case, discrepancies were shown not only in each hemisphere, but also in single continents on similar latitudes - for example in Europe. Different characters of trends for Europe were also shown in an analysis performed using radiosonde data conducted only for northern hemisphere (Ross and Elliot 2001). In that case, discrepancies were shown also for stations situated close to each other.

In this paper, the authors focus on ZTD, as a direct GPS product free from uncertainty connected to the interpolation of meteorological measurements (Schüler 2001) and used models, for both determining ZHD and converting ZWD to IWV (van Malderen et al. 2014). Thanks to homogenous set of the EUREF Permanent Network (EPN) data and due to coherent strategy for the satellite data processing, GPS ZTD time series can be used in researches related to the monitoring of climate changes and for climate model simulations (Pacione et al. 2014). Studies connected to variability of ZTD provide also information about the average local weather conditions, because 
size and character of these oscillations are related to such factors as latitude and height of the receiver or distance from big masses of water (Jin et al. 2007). To represent changes in the troposphere above Europe, data processed by Military University of Technology Local Analysis Centre (MUT LAC) consisting of 16-year times series determined for 59 EPN stations were used. For each station, the authors determined annual oscillations with their harmonic derivatives, and linear trend by means of Least Square Estimation (LSE). Trend with Mann-Kendall trend test to verify the results of the LSE was also detected. Studies related to climate change monitoring, based on GNSS long time series of homogeneous observations are one of tasks defined in the COST Action ES1206 "Advanced Global Navigation Satellite Systems tropospheric products for monitoring severe weather events and climate (GNSS4SWEC)".

\section{ZTD DATA}

Electromagnetic wave going through a neutral atmosphere is delayed, because of the refraction and tropospheric attenuation. The value of this delay is given in zenith direction and is defined as follows (Bevis et al. 1992):

$$
Z T D=\int_{H}^{+\infty}[n(z)-1] d z=10^{-6} \int_{H}^{+\infty} N(s) d z,
$$

where $n(z)$ is the atmospheric refractive index, and $N(z)$ is the atmospheric refractivity as a function of altitude $z$.

This delay is caused by hydrostatic part of the atmosphere (ZHD) and by wet part of the atmosphere (ZWD). In the case of GPS system, the size of these delays depends on total way along which the signal crosses the atmosphere (Slant Tropospheric Delay - STD) and hence, depends on of the satellite's zenith distance. To relate the size of delay from zenith direction (ZTD) to satellite direction (STD), mapping functions are being used. They provide a priori ZTD value and transfer it to STD, with takes into consideration different methods in mapping hydrostatic (ZHD) and wet (ZWD) part of the atmosphere. Mapping functions are approximately equal to $1 / \sin e$, where $e$ is the elevation angle, but in case of precise measurements it is required to use continued function given by Marini (1972), normalized and described by the formula (Herring 1992):

$$
m(f)=\frac{1+\frac{a}{1+\frac{b}{1+c}}}{\sin e+\frac{a}{\sin e+\frac{b}{\sin e+c}}},
$$


where $e$ is the elevation angle, and $a, b, c$ are coefficients related to the state of the troposphere.

Data used in the analysis comes from the EPN (Bruyninx 2004). This network was built on the basis of global geodetic network International GNSS Service (IGS) and plays a role of IGS densification in Europe. It has been working since 1996, and since that time it has been giving solutions for consecutives realizations of both ITRS and ETRS89 systems. Routine processing of the observations performed by the EPN network has been conducted by using different strategies, models, parameters and software, constantly since 1996, which caused collecting inhomogeneous data (coordinates and troposphere parameters). As a consequence, it was impossible to carry out a proper analysis of long time series obtained from EPN. Taking into account these problems and the fact that new, more precise products (like Earth rotation parameters or GPS satellite orbits) appeared, in 2007 it was decided to recalculate these data. This work, called Repro 1 campaign, was preceded by tests done simultaneously by the Royal Observatory of Belgium and the Military University of Technology. MUT reprocessing (Figurski et al. 2009, Söhne et al. 2010) included data from all EPN stations from January 1996 to December 2007 and used orbits and Earth Rotation Parameters (ERP) from the Potsdam-Dresden re-processing (Steigenberger et al. 2006) with the Bernese GPS software version 5.0 (Dach et al. 2007). Daily RINEX files containing less than $50 \%$ of possible observations were ignored. Residuals larger than $0.02 \mathrm{~m}$ were marked in a preprocessing step and removed in the final estimation. All stations with North East residuals greater than $10 \mathrm{~mm}$ and $\mathrm{Up}$ residuals greater than $20 \mathrm{~mm}$ were investigated and removed. Zenithal Total Delay was determined using Niell's mapping functions (Niell 1996) with $3^{\circ}$ elevation mask. After the Repro 1 campaign, MUT LAC has been providing solutions only for one of EPN subnets. Consequently, we had a set of homogeneous data (from all EPN network) only to the end of 2007 and after this year, only for those stations that have been allocated in MUT LAC. Therefore, out of the time series available from the whole EPN network, we picked those stations which started operating no later than 1998, and then for stations that have not been attached to MUT LAC (located in different subnets) we determined coordinates and troposphere parameters, according to the MUT LAC Repro 1 strategy. Thanks to consistent calculating strategy used for all observations, we received at least 16-year homogeneous time series of hourly solutions, which are an essential element in research connected with long time climate trend (Bengtsson et al. 2004) for 59 EPN stations (Fig. 1 and Table 1 in the Appendix). 
$21^{\circ} \mathrm{W} \quad 17^{\circ} \mathrm{W} \quad 13^{\circ} \mathrm{W} \quad 9^{\circ} \mathrm{W} \quad 5^{\circ} \mathrm{W} \quad 1^{\circ} \mathrm{W} \quad 3^{\circ} \mathrm{E} \quad 7^{\circ} \mathrm{E} \quad 11^{\circ} \mathrm{E} \quad 15^{\circ} \mathrm{E} \quad 19^{\circ} \mathrm{E} \quad 23^{\circ} \mathrm{E} \quad 27^{\circ} \mathrm{E} \quad 31^{\circ} \mathrm{E} \quad 35^{\circ} \mathrm{E} \quad 39^{\circ} \mathrm{E}$

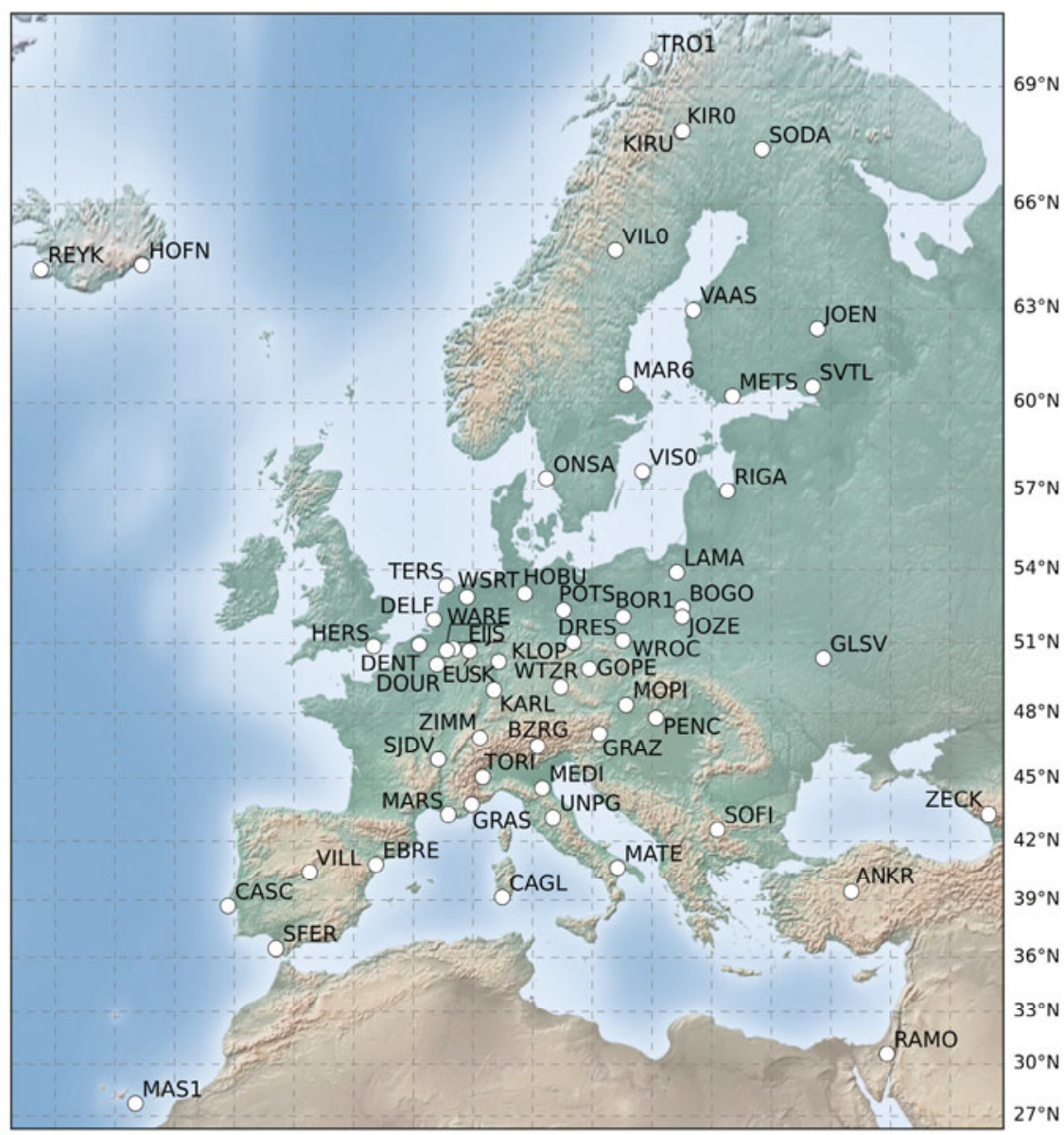

Fig. 1. Distribution of analyzed EPN stations (January 1998 - December 2013).

\section{DATA PREPARATION FOR FURTHER ANALYSIS: ASSESSMENT AND SCREENING OF THE ZTD TIME SERIES}

The quality of ZTD time series is very important due to the nature of investigated changes (e.g., linear trend). One of most important parameters which have significant influence on the credibility of the values is the length of the time series. In the analysis, data from EPN stations, which have been leading observations since 1998, were used. Thanks to the coherent processing strategy adopted from the Repro 1 campaign and subsequent calculations, long (16- to 18-year) ZTD time series were received. However due to the fact that linear trend in ZTD time series is sensitive to the selected time period (Nilsson and Elgered 2008), the authors decided to shorten 


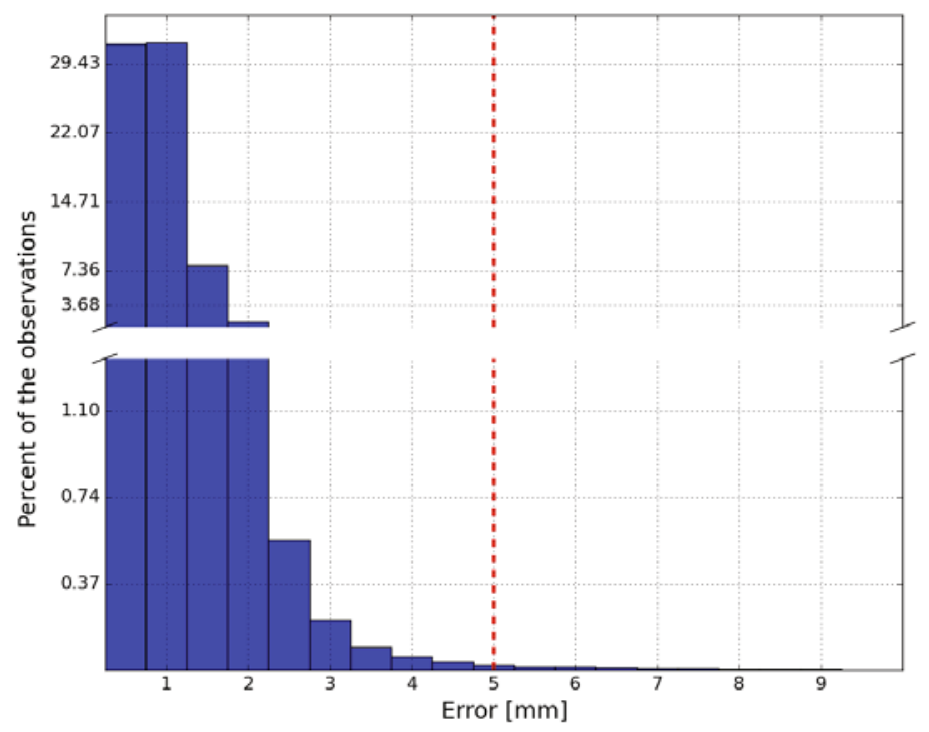

Fig. 2. Histogram of the uncertainty for ZTD solutions (16 years, 59 EPN stations).

longer time series (for stations which have been operating since January 1996) to period of January 1998 - December 2013 to ensure their coherence. For this period, all ZTD solutions for which coordinates were not fixed properly were rejected and all data with error larger than $5 \mathrm{~mm}$ were removed. Figure 2 presents histogram of ZTD error for all the solutions. Most of them is in the 1-2 $\mathrm{mm}$ range. Red dashed line shows the $5 \mathrm{~mm}$ reject criterion and the number of solutions that were removed from further analysis.

The next step in data screening was the rejection of stations whose time series were characterized by a low number of solutions in relation to their theoretical maximum number. The number of available solutions was on an average level of $95.36 \%$ of the theoretical number of solutions. Available solutions which fulfill the criterion of $5 \mathrm{~mm}$ account for about $95.10 \%$ of the theoretical number of solutions. The best quality of the time series has the DELF station. The number of solutions available for this station accounts for $99.58 \%$ of the theoretical number of solution and the available number of solutions that fulfill the criterion of $5 \mathrm{~mm}$ accounts for $99.51 \%$ of the theoretical number of solution. The worst quality has ANKR station, with the number of available solutions and the number of available solutions that meet the $5 \mathrm{~mm}$ criterion at the level of 82.82 and $81.42 \%$, respectively. Because the ANKR has less than $90 \%$ of the theoretical number of solutions, this station was removed from further analysis. 


\section{ANALYSIS OF ZTD TIME SERIES}

In order to determine the value of linear trend in ZTD time series, seasonal variations, like, e.g., annual and semi-annual oscillations were taken into consideration. Time series of stations refer to exactly the same period (19982013) but they have some gaps in data; therefore, to obtain information about oscillation, the Lomb-Scargle periodogram was prepared for every station (Hocke 1998). This method estimates frequency spectrum by fitting linear least-squares of sine and cosine model to the observed time series (Lomb 1976, Press et al. 1992):

$$
x\left(t_{i}\right)=a \cos \left(\omega t_{i}-\Theta\right)+b \sin \left(\omega t_{i}-\Theta\right)+n_{i},
$$

where $x\left(t_{i}\right)$ is the observed time series at time $t_{i}, a$ and $b$ are constant amplitudes, $\omega$ is the angular frequency, $\Theta$ is additional phase (required for the orthogonalization of the sine and cosine model functions when the data are unevenly spaced), and $n_{i}$ is the noise at time $t_{i}$.

Periodograms show various oscillations and characters of time series, because stations involved in the analysis are spread throughout Europe and different average weather conditions had influence on the ZTD size. All stations have a clear annual oscillation, and most of them have clear semiannual oscillations. However, some of them have also other variations or different configurations of variations (e.g., without semi-annual oscillations). For every station 2 periodograms were prepared (with and without annual oscillation), due to strong annual oscillations which disturb the character of oscillations with smaller amplitude and thus hinder their investigation. Figure 3 shows Lomb-Scargle periodograms for the ZTD time series for selected stations. Station GRAS (Fig. 3a) has clearly only annual oscillation with amplitude $41.7 \mathrm{~mm}$ (a similar character have, e.g., MARS and CAGL stations). Significant annual and semi-annual oscillations has, e.g., the GLSV station (Fig. 3b) with amplitude 53.3 and $10.6 \mathrm{~mm}$, respectively. In some cases, semi-annual oscillations were smaller than oscillations with $1 / 3$ year frequency - like SFER (Fig. 3c) with amplitudes of 24.2, 4.6, and $7.0 \mathrm{~mm}$ for annual, semi-annual, and ter-annual oscillations, respectively. MAS1 station (Fig. 3d) has noticeable annual, semi-annual, ter-annual, and even quarto-annual amplitudes with $29.9,7.9,5.8$, and $2.5 \mathrm{~mm}$, respectively. In case of RAMO station (Fig. 3e) semi-annual and ter-annual oscillations have significant value of amplitude as compared to the value of annual oscillation amplitude.

Based on the results from the periodograms analysis, estimation of the linear trend and seasonal components was carried out using the model:

$$
\begin{aligned}
x(t)= & x_{0}+v_{x} t+A_{A}^{I} \sin 2 \pi t+A_{A}^{O} \cos 2 \pi t+A_{S A}^{I} \sin 4 \pi t+A_{S A}^{O} \cos 4 \pi t \\
& +A_{T A}^{I} \sin 6 \pi t+A_{T A}^{O} \cos 6 \pi t+A_{Q A}^{I} \sin 8 \pi t+A_{Q A}^{O} \cos 8 \pi t,
\end{aligned}
$$


a

GRAS
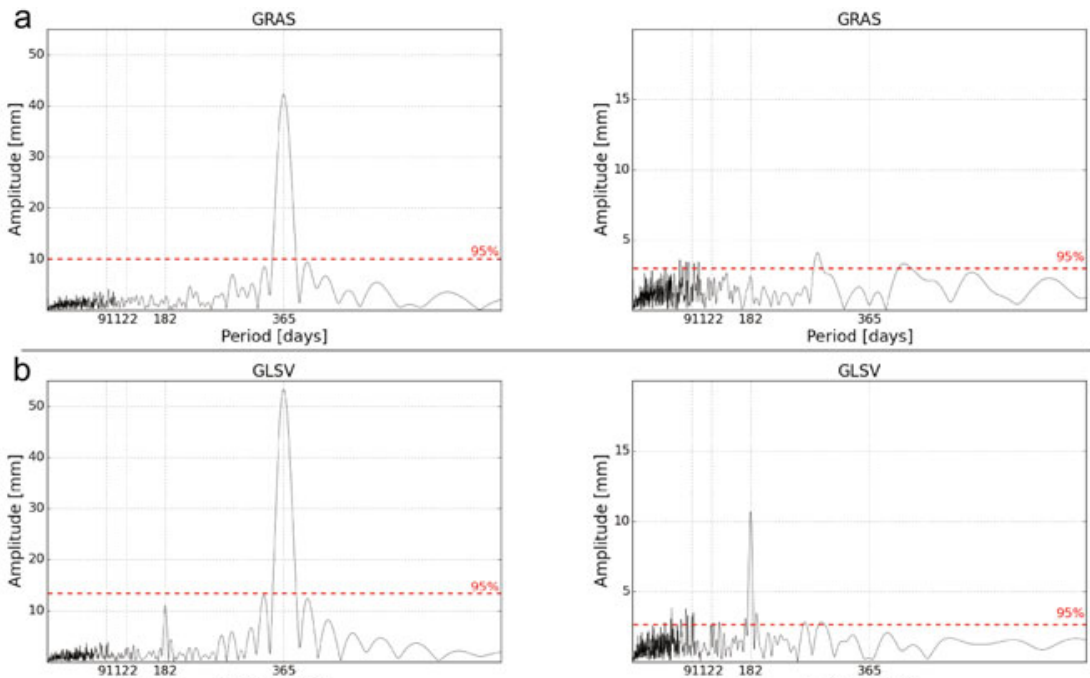

Period [days]

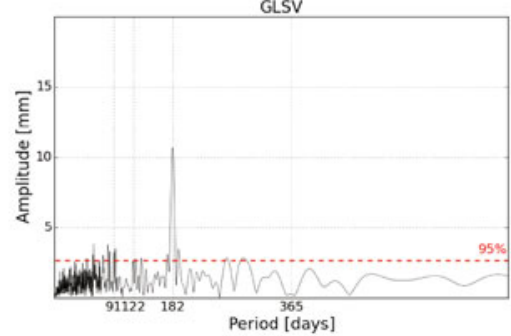

C

SFER

SFER
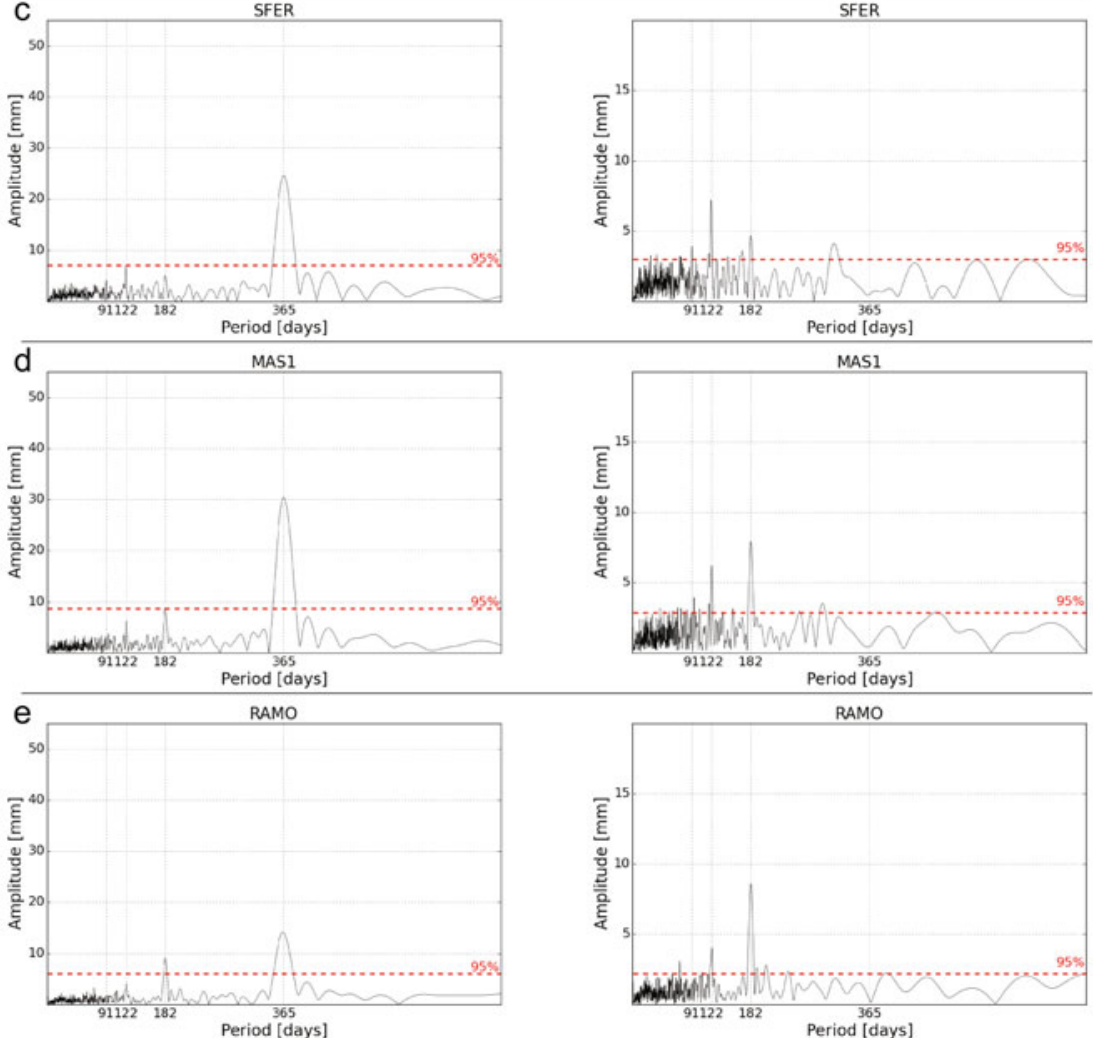

Fig. 3. Lomb-Scargle periodograms for GRAS (a), GLSV (b), SFER (c), MAS1 (d), and RAMO (e) stations. 
where $x(t)$ is the observed time series, $v_{x} t$ is the linear trend, $A_{A}^{I}, A_{A}^{O}$, etc. are coefficients for the condition of sine and cosine using the method of least squares. The LSE trend and amplitude of annual, semi-annual, ter-annual, and quarto-annual term (obtained from Lomb-Scarge periodograms) were calculated on the basis of hourly data (results in Section 5).

In order to verify the trend estimated using LSE modified Mann-Kendall trend test (Mann 1945, Kendall and Stuart 1970) for all stations was also prepared. Mann-Kendall trend test is a statistical, non-parametric test which can be used for trend detection in climatologic time series (Goosens and Berger 1986, Mavromatis and Stathis 2011) due to the fact that it does not require time series with normally distributed data and has low sensitive to gaps in data (Karmeshu 2012). The test execution returns information about whether a trend exists (hypothesis True) or whether the data is random and independent of each other, and because of that there is no trend in time series (hypothesis False). In addition, MK trend test returns the value of a statistical factor $S$, whose character (positive or negative) reflects character of trend in the time series:

$$
\begin{gathered}
S=\sum_{i=1}^{n-1} \sum_{j=i+1}^{n} \operatorname{sign}\left(X_{j}-X_{i}\right) \\
\operatorname{sign}\left(X_{j}-X_{i}\right)=\left\{\begin{array}{c}
1 \text { if } X_{j}-X_{i}>0 \\
0 \text { if } X_{j}-X_{i}=0 \\
-1 \text { if } X_{j}-X_{i}<0
\end{array}\right.
\end{gathered}
$$

where $X_{j}$ and $X_{i}$ are time series, with $i=1,2,3, \ldots, n-1$ and $j=i+1, i+2$, $i+3, \ldots, n$.

In case of described analysis, the MK trend test for time series with deleted oscillations (annual, semi-annual, ter-annual, quarto-annual) was performed. The MK trend test does not give result as a value of trend, but it is useful in case of these stations which due to the low value of the trend (obtained by the LSE) require additional verification.

\section{RESULTS OF ANALYSIS}

\subsection{6-year time series}

In this paper we focused on 16-year ZTD time series, mostly due to the fact that, assuming the need to analyze exactly the same period of time for all stations, their spatial resolution is better than in the case of 18-year time series (more stations). Based on the results obtained from Lomb-Scargle periodo-grams and LSE method, annual, semi-annual, ter-annual, and quarto-annual oscillations for every station were estimated. The average size of the annual oscillation amplitude (for all stations) is on the level of 
$46.8 \mathrm{~mm}$, with maximum value for TORI station and minimum value for RAMO station, which are 63.3 and $13.72 \mathrm{~mm}$, respectively. Average amplitude of semi-annual oscillations is $7.5 \mathrm{~mm}$, with maximum value for JOEN station $(11.9 \mathrm{~mm})$. For some stations (e.g., MATE) this oscillation does not exist. These amplitudes are similar, but a little smaller than average global values for annual and semi-annual oscillations given by Jin (Jin et al. 2007), which are 50 and $10 \mathrm{~mm}$, respectively. Different characters of time series, deter-mined by different size of seasonal components, are shown in Figs. 4 and 5. Small amplitude of annual variations $(22.6 \mathrm{~mm})$ for CASC station (Fig. 4) in combination with one of the highest average ZTD values $(2.425 \mathrm{~m})$ reflects climate character in area of this station. It is located in Portugal, on the coast of the Atlantic Ocean in the humid subtropical zone, where high humidity and lack of large temperature variations are probably due to the influence of the Gulf Stream. In contrast, GRAS station (Fig. 5) with the $41.8 \mathrm{~mm}$ of annual amplitude and the lowest average ZTD value $(2.054 \mathrm{~mm})$ represents the conditions corresponding to large heights (station is located at $1319.3 \mathrm{~m}$ a.s.1.).

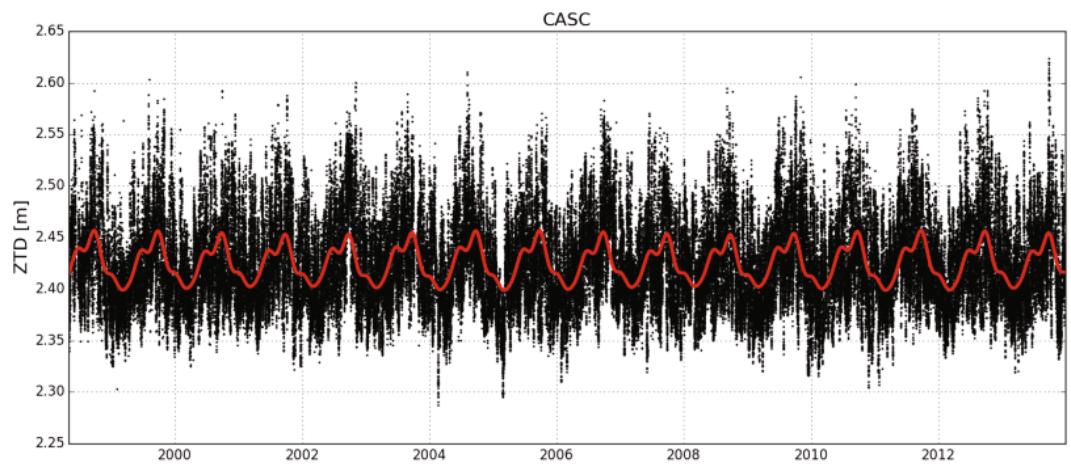

Fig. 4. ZTD time series for CASC (Portugal) station with fitted oscillations.

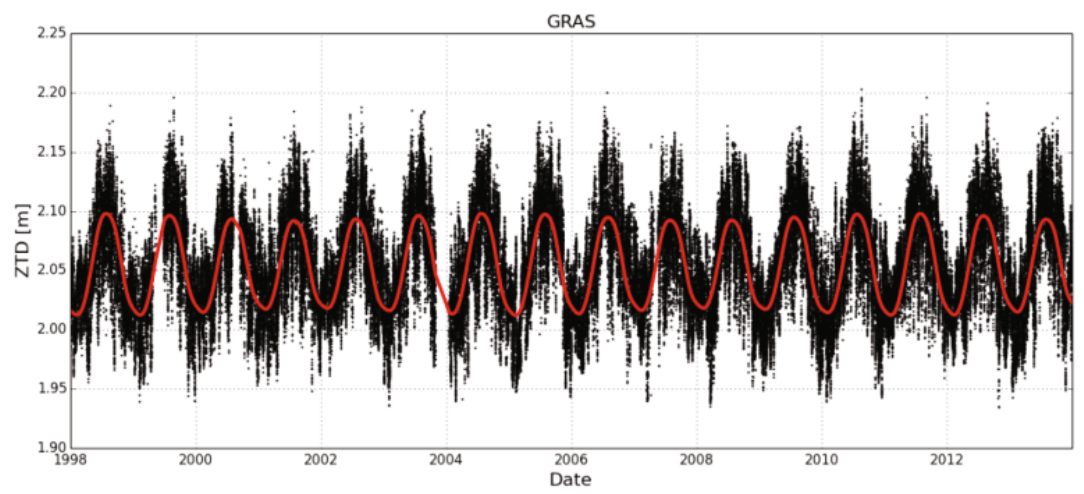

Fig. 5. ZTD time series for GRAS (France) station with fitted oscillations. 
$21^{\circ} \mathrm{W} \quad 17^{\circ} \mathrm{W} \quad 13^{\circ} \mathrm{W} \quad 9^{\circ} \mathrm{W} \quad 5^{\circ} \mathrm{W} \quad 1^{\circ} \mathrm{W} \quad 3^{\circ} \mathrm{E} \quad 7^{\circ} \mathrm{E} \quad 11^{\circ} \mathrm{E} \quad 15^{\circ} \mathrm{E} \quad 19^{\circ} \mathrm{E} \quad 23^{\circ} \mathrm{E} \quad 27^{\circ} \mathrm{E} \quad 31^{\circ} \mathrm{E} \quad 35^{\circ} \mathrm{E} \quad 39^{\circ} \mathrm{E}$



Fig. 6. Amplitude and phase shift for annual ZTD oscillations (January 1998 December 2013).

Seasonal components of ZTD time series, like annual variations, could be useful for climate applications, especially with taking into consideration size of their amplitude and phase shift (month with maximum value of sinusoid). Variations of ZTD are mostly determined by wet component of troposphere. Their maximum amplitude is usually correlated with maximum temperature and humidity. Figure 6 shows size of amplitude, with an indication of the time when the amplitude reaches a maximum. For most of the station it is in the end of July or in the beginning of August, which coincides with the summer months in which the highest temperatures are observed. 




Fig. 7. ZTD trend for 16-year time series (January 1998 - December 2013).

Trend detection in ZTD long time series has very high value for climate change monitoring. Using LSE, the trend value was determined and the existence of trend was confirmed by means of Mann-Kendall method. Only in the case when the Mann-Kendall test confirmed the existence of a trend (True), the station was taken for further analysis. From 58 EPN stations, using both above-mentioned methods, the occurrence of a trend was confirmed for 54 stations. Stations without proven trend are: CASC, MATE, MEDI, TORI. The average value of trend (for the rest of stations) is $1.0 \mathrm{~mm} /$ decade, but this value includes both positive and negative trends. 34 stations have positive trend and 19 stations negative. The highest positive trend was found for the BZRG station and its size is $5.5 \mathrm{~mm} / \mathrm{decade}$. The most negative trend was found for GOPE station and its size is $-4.7 \mathrm{~mm} /$ decade. Figure 7 shows 
location, size, and type of determined trend. Green arrows indicate positive trends, and red arrows indicate negative. For the north-eastern part of Europe, the trend characters are the same (positive), only with some discrepancies to the size of ZTD trend. The largest discrepancies to the nature of the trend occurred in Central-Western Europe, where in Western Germany, Belgium, Nederland, and Eastern France is the

superiority of stations with a negative trend. These negative trends are small in magnitude but occur in almost every station. Their meridional distribution may indicate that the distribution of air masses in the summer months is responsible for the changes in the ZTD values. In July, the circulation of air over continental part of Europe is based largely on the Azores High (highpressure zone over Atlantic) and low-pressure zone over Eurasian. Maximum range of occurrences of these both atmospheric pressure centers has also a meridian run (which is variable over time), coinciding with the occurrence of these negative trends. Perhaps in the analyzed period of time the average range of one of these atmospheric pressure centers has been changed and that could be reflected in changes of average ZTD values (negative trends). Most of the other stations which are characterized by negative trends (GOPE, DRES, WROC, MOPI, UNPG, VILL) lie near the mountains which very often have a different type of climate, which may cause discrepancies in trends' character.

All results (annual amplitude, semi-annual amplitude, trend, mv, and Mann-Kendall trend test results) for 16-year ZTD time series are presented in Table 2 in the Appendix.

\subsection{Comparison of 16- and 18-year ZTD time series}

Indicated by Nilsson and Elgered (2008) necessity of data from exactly the same period analysis imposes the need to reduce the time series in order to achieve the most optimal spatial resolution. On the other hand, determination of the trend should be based on the longest possible observations. The twoyear difference in the length of the time series may be important not only in relation to the estimated size of the trend, but also as to its character. In EPN network 30 stations have at least 18-year ZTD time series (they have been operating since 1996) and for these stations a comparison between shortened 16- and full 18-year ZTD time series has been prepared.

Annual amplitudes for 18-year ZTD time series are different than in case of 16-year time series for every station. Size of amplitudes for longer period of time are smaller than in case of shorter period of time, but these differences are less than $1 \mathrm{~mm}$. Semi-annual amplitudes for 18-year time series are also different than for 16-year time series (except RAMO station) for every station. In contrast to the annual amplitudes, larger size of semi-annual am- 
plitudes occurs in most of the stations for longer period of time. However these differences are also less than $1 \mathrm{~mm}$.

For 4 stations MK trend test gave different result for 16-year time series than in case of 18-year time series. In case of DELF and WARE the result of MK trend test was positive (True) for shorter period of time and negative (False) for longer period of time. In case of MATE and MEDI result of MK trend test was negative (False) for shorter period of time and positive (True) for longer period of time. Differences in the number of stations for which the trend has been confirmed (for both lengths of time series), confirms that in order to analyze the changes in the spatial distribution of ZTD, it is necessary to work on the exact same period of time. This is due to the fact that for small value of the trend and time series not long enough, an additional one or two seasons with stronger or weaker weather conditions than usual, may noticeably affect the size of trend. Average value of trend, for rest 26 stations, is $1.5 \mathrm{~mm} /$ decade for 16 -year time series and $2.0 \mathrm{~mm} /$ decade for 18 -year time series. For 4 stations (MAS1, MOPI, RAMO, RIGA) values of trends are exactly the same for two periods of time and are 3.0, -0.1, 3.3, and $5.0 \mathrm{~mm} /$ decade, respectively. For ZIMM station value of trend for 16-year time series is negative $(-0.4 \mathrm{~mm} /$ decade $)$ and for 18 -year time series is positive $(1.2 \mathrm{~mm} /$ decade), whereas for both time series result of MK trend test is positive (True). In case of this station confidence interval is better for longer period of time, however the size of linear trend for shortened period of time is quite small and probably a slight change in the average weather conditions in additional two years might affect this change. An example of this station shows how sensitive to the changes, depending on the length of time series, the ZTD parameter is. Figure 8 represents all differences between results in trend value obtained from 18- and 16-year time series for 30 EPN stations.

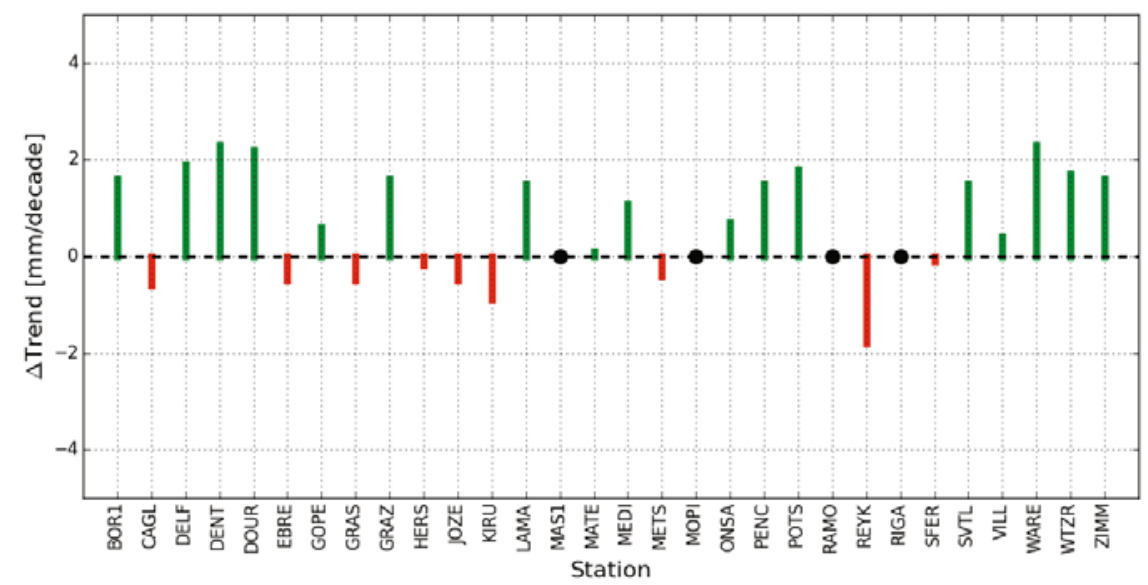

Fig. 8. Differences in trend value for 18- and 16-year time series. 
$21^{\circ} \mathrm{W} \quad 17^{\circ} \mathrm{W} \quad 13^{\circ} \mathrm{W} \quad 9^{\circ} \mathrm{W} \quad 5^{\circ} \mathrm{W} \quad 1^{\circ} \mathrm{W} \quad 3^{\circ} \mathrm{E} \quad 7^{\circ} \mathrm{E} \quad 11^{\circ} \mathrm{E} \quad 15^{\circ} \mathrm{E} \quad 19^{\circ} \mathrm{E} \quad 23^{\circ} \mathrm{E} \quad 27^{\circ} \mathrm{E} \quad 31^{\circ} \mathrm{E} \quad 35^{\circ} \mathrm{E} \quad 39^{\circ} \mathrm{E}$



Fig. 9. ZTD trend for 18-year time series (January 1996 - December 2013).

All results for 18-year ZTD time series are presented in Table 2 in the Appendix. In addition the results of linear trends estimated based on 18years ZTD time series are presented in Fig. 9.

Long time series obtained from 30 EPN stations indicate the advantage of a positive trend in Europe. Only 4 stations (DENT, DOUR, GOPE, VILL) have negative character of trend and 26 stations have positive character of trend. For 2 stations (DELF, WARE), the MK trend test gave a negative result (False). The highest positive trend has RIGA station, which is $5.0 \mathrm{~mm} /$ decade. The most negative trend has (as in 16-year time series) GOPE station, which is $-4.7 \mathrm{~mm} /$ decade. As in the case of 16-year time series, discrepancies exist in Central-Western Europe, although they are less 
significant. Primarily, a smaller number of stations in this area could be included in the 18-year analysis (due to too short time series), but on the other hand the size of the trends, at the stations which were subjected to analysis, is lower than in the case of 16-year ZTD time series.

The comparison showed the importance of additional two years of observations for the value of linear trend. The vast majority of stations is represented by a different size of the trend for the 16- and 18-year time series and one of stations has even different nature of trend. This shows how important for climate application is using the longest possible, but at the same time preserving the homogeneity, time series.

\section{SUMMARY}

In this paper, long ZTD time series were analyzed. Seasonal components (annual, semi-annual, ter-annual, quarto-annual) and linear trend were found using LSE. In order to obtain information about the oscillations, LombScargle periodograms were performed for every station. Removed annual amplitude from time series allowed to reduce impact that it has on the oscillations with smaller amplitude and thus their correct verification. This approach is relevant for the analysis of a station with large spatial distribution, where the characters of the time series are significantly different from each other mainly due to different weather conditions.

The highest annual amplitude was found for TORI station $(63.3 \mathrm{~mm})$ and the lowest for RAMO station $(13.7 \mathrm{~mm})$. The highest semi-annual amplitude was found for JOEN station $(11.9 \mathrm{~mm})$ and for some stations this oscillation does not exist (e.g., $0.6 \mathrm{~mm}$ for MATE station). The nature of the occurring oscillations represents the average weather conditions prevailing in the area. High amplitude of annual oscillations is related to the continental or mountain type of climate, where the moderating influence of the warm mass of water is limited. It is probable that changes in the size of annual oscillations (increasing or decreasing from year to year) may reflect changes in the range of impact on the continent different type of climate, as well as linear trend. The decreasing size of amplitude may be caused by the increasing influence of the warm water masses on average weather conditions. However, the study of such dependence requires other tools and methods than LSE approach.

In the case of a linear trend, results should be considered in two categories: 16-year time series and 18-year time series to assess the impact of additional two years. For 16-year ZTD time series the highest positive and the most negative trends have BZRG and GOPE stations, with $5.5 \mathrm{~mm} /$ decade and $-4.7 \mathrm{~mm} /$ decade, respectively. For 18 -year ZTD time series the highest positive and the most negative trends have RIGA and GOPE stations, with $5.0 \mathrm{~mm} /$ decade and $-4.1 \mathrm{~mm} /$ decade, respectively. For ZIMM station the 
character of trend for 16-year ZTD data is against the character of the trend for 18-year ZTD data. There are also considerable differences in the size of the trend between two periods of time, which in case of linear trend spatial distribution analysis (important for climate applications), indicates the necessity of use data from exactly the same period of time.

To verify the existence of the trend obtained by LSE method, MK trend test was also performed. This test is particularly useful for stations with a small value of trend designated with LSE. Because MK trend test gave positive results for the verification of the existence of the trends, despite the divergence in their values and characters, the way of interpreting the trend becomes particularly important. Due to the fact that two years may have a significant effect on the character and magnitude of the changes, they should be seen not only in the category of linear change, but also in the category of successive short-term changes (year after year). As in the case of observation of amplitudes changes, this task requires the use of more tools than just LSE method.

Interpretation of the results is ambiguous because of the very large variety of climate types found in Europe, as well as harshness of the terrain, but taking into account the basic aspects arising from locations of the stations, many discrepancies in a trend character can be explained. It should be emphasized that the length of time series is still not sufficient for full climate research. However, on the one hand the development of appropriate methods of obtaining and interpreting results is important from the point of view of the possibility of adjusting constantly developing GNSS technology for the purpose of examining the troposphere. On the other hand, almost 20-year time series can be a sufficient source of data for supplementing and validating the climate models.

Acknowledgments. This research was financed by the Faculty of Civil Engineering and Geodesy of the MUT statutory research funds. The authors would like to acknowledge the contribution of the COST Action ES1206. 
Appendix

The list of EPN stations and the results

Table 1

The list of EPN stations taken for analysis

\begin{tabular}{|c|c|c|c|c|c|c|c|}
\hline Station & \begin{tabular}{|c} 
Latitude \\
[deg.]
\end{tabular} & $\begin{array}{c}\text { Longitude } \\
\text { [deg.] }\end{array}$ & $\begin{array}{c}H \\
{[\mathrm{~m}]}\end{array}$ & Station & $\begin{array}{c}\text { Latitude } \\
\text { [deg.] }\end{array}$ & \begin{tabular}{|c} 
Longitude \\
[deg.]
\end{tabular} & $\begin{array}{c}H \\
{[\mathrm{~m}]}\end{array}$ \\
\hline ANKR & 39.89 & 32.76 & 974.8 & MATE & 40.65 & 16.70 & 535.6 \\
\hline BOGO & 52.48 & 21.04 & 149.6 & MEDI & 44.52 & 11.65 & 50.0 \\
\hline BOR1 & 52.10 & 17.07 & 124.0 & METS & 60.22 & 24.40 & 94.6 \\
\hline BZRG & 46.50 & 11.34 & 328.8 & MOPI & 48.37 & 17.27 & 579.0 \\
\hline CAGL & 39.14 & 8.97 & 238.4 & ONSA & 57.40 & 11.93 & 45.5 \\
\hline CASC & 38.69 & -9.42 & 77.1 & PENC & 47.79 & 19.28 & 291.7 \\
\hline DELF & 51.99 & 4.39 & 74.4 & POTS & 52.38 & 13.07 & 174.0 \\
\hline DENT & 50.93 & 3.40 & 63.9 & RAMO & 30.60 & 34.76 & 893.1 \\
\hline DOUR & 50.09 & 4.59 & 283.0 & REYK & 64.14 & -21.96 & 93.1 \\
\hline DRES & 51.03 & 13.73 & 202.9 & RIGA & 56.95 & 24.06 & 34.7 \\
\hline EBRE & 40.82 & 0.49 & 107.9 & SFER & 36.46 & -6.21 & 85.8 \\
\hline EIJS & 50.76 & 5.68 & 103.8 & SJDV & 45.89 & 4.68 & 336.0 \\
\hline EUSK & 50.67 & 6.76 & 245.3 & SODA & 67.42 & 26.39 & 299.7 \\
\hline GLSV & 50.36 & 30.50 & 226.8 & SOFI & 42.56 & 23.39 & 1119.6 \\
\hline GOPE & 49.91 & 14.79 & 592.6 & SVTL & 60.53 & 29.78 & 77.1 \\
\hline GRAS & 43.75 & 6.92 & 1319.3 & TERS & 53.36 & 5.22 & 56.1 \\
\hline GRAZ & 47.07 & 15.49 & 538.3 & TORI & 45.06 & 7.66 & 310.4 \\
\hline HERS & 50.87 & 0.34 & 76.5 & TRO1 & 69.66 & 18.94 & 138.0 \\
\hline HOBU & 53.05 & 10.48 & 152.3 & UNPG & 43.12 & 12.36 & 351.2 \\
\hline HOFN & 64.27 & -15.19 & 82.5 & VAAS & 62.96 & 21.77 & 58.0 \\
\hline JOEN & 62.39 & 30.10 & 113.7 & VIL0 & 64.70 & 16.56 & 449.9 \\
\hline JOZE & 52.10 & 21.03 & 141.4 & VILL & 40.44 & -3.95 & 647.5 \\
\hline KARL & 49.01 & 8.41 & 182.9 & VIS0 & 57.65 & 18.37 & 79.8 \\
\hline KIR0 & 67.88 & 21.06 & 497.9 & WARE & 50.69 & 5.25 & 188.0 \\
\hline KIRU & 67.86 & 20.97 & 391.1 & WROC & 51.11 & 17.06 & 181.0 \\
\hline KLOP & 50.22 & 8.73 & 222.4 & WSRT & 52.91 & 6.60 & 86.0 \\
\hline LAMA & 53.89 & 20.67 & 187.0 & WTZR & 49.14 & 12.88 & 666.0 \\
\hline MAR6 & 60.60 & 17.26 & 75.4 & ZECK & 43.29 & 41.57 & 1166.8 \\
\hline MARS & 43.28 & 5.35 & 61.8 & ZIMM & 46.88 & 7.47 & 956.7 \\
\hline MAS1 & 27.76 & -15.63 & 197.3 & & & & \\
\hline
\end{tabular}


Table 2

Results of analysis of 16- and 18-year ZTD time series.

Bolded trend values represent positive result of Mann-Kendall trend test.

\begin{tabular}{|c|c|c|c|c|c|c|c|c|}
\hline \multirow[t]{2}{*}{ Station } & $\begin{array}{c}\text { Mean } \\
\text { ZTD } \\
{[\mathrm{m}]}\end{array}$ & $\begin{array}{l}\text { Annual } \\
\text { ampli- } \\
\text { tude } \\
{[\mathrm{mm}]}\end{array}$ & $\begin{array}{l}\text { Semi- } \\
\text { annual } \\
\text { ampli- } \\
\text { tude } \\
{[\mathrm{mm}]}\end{array}$ & $\begin{array}{c}\text { Trend value } \\
\pm \text { error } \\
\text { [mm/year] }\end{array}$ & $\begin{array}{c}\text { Mean } \\
\text { ZTD } \\
{[\mathrm{m}]}\end{array}$ & $\begin{array}{c}\text { Annual } \\
\text { ampli- } \\
\text { tude } \\
{[\mathrm{mm}]}\end{array}$ & $\begin{array}{c}\text { Semi- } \\
\text { annual } \\
\text { ampli- } \\
\text { tude } \\
{[\mathrm{mm}]}\end{array}$ & $\begin{array}{c}\text { Trend value } \\
\pm \text { error } \\
\text { [mm/year] }\end{array}$ \\
\hline & \multicolumn{4}{|c|}{ 16-year ZTD time series } & \multicolumn{4}{|c|}{ 18-year ZTD time series } \\
\hline BOGO & 2.374 & 52.65 & 9.44 & $0.45 \pm 0.02$ & & & & \\
\hline BOR1 & 2.385 & 51.85 & 9.42 & $0.14 \pm 0.02$ & 2.385 & 51.80 & 9.62 & $0.30 \pm 0.02$ \\
\hline BZRG & 2.347 & 62.04 & 6.36 & $0.55 \pm 0.02$ & & & & \\
\hline CAGL & 2.376 & 37.63 & 3.42 & $0.22 \pm 0.02$ & 2.376 & 37.88 & 2.83 & $0.16 \pm 0.02$ \\
\hline CASC & 2.425 & 22.57 & 1.69 & $-0.03 \pm 0.02$ & & & & \\
\hline DELF & 2.405 & 43.89 & 7.94 & $-0.18 \pm 0.02$ & 2.405 & 43.76 & 8.06 & $0.01 \pm 0.02$ \\
\hline DENT & 2.412 & 43.98 & 7.63 & $-0.28 \pm 0.02$ & 2.411 & 43.78 & 7.89 & $-0.05 \pm 0.02$ \\
\hline DOUR & 2.346 & 43.92 & 7.68 & $-0.26 \pm 0.02$ & 2.346 & 43.50 & 7.96 & $-0.04 \pm 0.02$ \\
\hline DRES & 2.370 & 50.89 & 8.42 & $-0.23 \pm 0.02$ & & & & \\
\hline EBRE & 2.425 & 54.21 & 8.94 & $0.27 \pm 0.02$ & 2.424 & 54.28 & 9.13 & $0.22 \pm 0.02$ \\
\hline EIJS & 2.402 & 46.00 & 8.12 & $-0.37 \pm 0.02$ & & & & \\
\hline EUSK & 2.358 & 46.36 & 7.91 & $-0.20 \pm 0.02$ & & & & \\
\hline GLSV & 2.352 & 53.26 & 10.60 & $0.53 \pm 0.02$ & & & & \\
\hline GOPE & 2.255 & 48.76 & 8.40 & $-0.47 \pm 0.02$ & 2.255 & 48.45 & 8.54 & $-0.41 \pm 0.02$ \\
\hline GRAS & 2.055 & 41.77 & 2.46 & $0.19 \pm 0.02$ & 2.054 & 41.61 & 3.13 & $0.14 \pm 0.02$ \\
\hline GRAZ & 2.281 & 56.33 & 8.06 & $0.12 \pm 0.02$ & 2.281 & 55.47 & 8.39 & $0.28 \pm 0.02$ \\
\hline HERS & 2.406 & 40.95 & 7.85 & $0.42 \pm 0.02$ & 2.405 & 40.95 & 8.28 & $0.40 \pm 0.02$ \\
\hline HOBU & 2.377 & 47.10 & 8.11 & $-0.04 \pm 0.02$ & & & & \\
\hline HOFN & 2.36 & 42.48 & 6.67 & $-0.41 \pm 0.02$ & & & & \\
\hline JOEN & 2.349 & 53.53 & 11.91 & $0.31 \pm 0.02$ & & & & \\
\hline JOZE & 2.380 & 52.85 & 10.48 & $0.41 \pm 0.02$ & 2.380 & 52.77 & 10.65 & $0.36 \pm 0.02$ \\
\hline KARL & 2.386 & 49.62 & 8.43 & $-0.22 \pm 0.02$ & & & & \\
\hline KIR0 & 2.224 & 49.49 & 9.46 & $0.12 \pm 0.02$ & & & & \\
\hline KIRU & 2.253 & 50.33 & 10.05 & $0.19 \pm 0.02$ & 2.253 & 49.94 & 11.14 & $0.10 \pm 0.02$ \\
\hline KLOP & 2.367 & 47.28 & 7.85 & $-0.38 \pm 0.02$ & & & & \\
\hline LAMA & 2.359 & 52.18 & 9.73 & $0.27 \pm 0.02$ & 2.358 & 51.76 & 9.84 & $0.42 \pm 0.02$ \\
\hline MAR6 & 2.370 & 50.61 & 9.34 & $0.37 \pm 0.02$ & & & & \\
\hline MARS & 2.419 & 44.30 & 1.21 & $0.20 \pm 0.02$ & & & & \\
\hline MAS1 & 2.392 & 29.87 & 7.92 & $0.30 \pm 0.02$ & 2.392 & 29.81 & 7.47 & $0.30 \pm 0.02$ \\
\hline MATE & 2.283 & 41.1 & 0.56 & $0.02 \pm 0.02$ & 2.283 & 40.97 & 0.62 & $0.03 \pm 0.01$ \\
\hline MEDI & 2.43 & 54.48 & 3.52 & $0.04 \pm 0.02$ & 2.430 & 54.09 & 4.37 & $0.15 \pm 0.02$ \\
\hline METS & 2.36 & 50.41 & 9.11 & $0.31 \pm 0.02$ & 2.360 & 49.92 & 9.76 & $0.27 \pm 0.02$ \\
\hline
\end{tabular}


Table 2 (continuation)

\begin{tabular}{|c|c|c|c|c|c|c|c|c|}
\hline \multirow[t]{2}{*}{ Station } & $\begin{array}{l}\text { Mean } \\
\text { ZTD } \\
{[\mathrm{m}]}\end{array}$ & $\begin{array}{c}\text { Annual } \\
\text { ampli- } \\
\text { tude } \\
{[\mathrm{mm}]}\end{array}$ & $\begin{array}{l}\text { Semi- } \\
\text { annual } \\
\text { ampli- } \\
\text { tude } \\
{[\mathrm{mm}]}\end{array}$ & $\begin{array}{c}\text { Trend value } \\
\pm \text { error } \\
\text { [mm/year] }\end{array}$ & $\begin{array}{l}\text { Mean } \\
\text { ZTD } \\
{[\mathrm{m}]}\end{array}$ & $\begin{array}{l}\text { Annual } \\
\text { ampli- } \\
\text { tude } \\
{[\mathrm{mm}]}\end{array}$ & $\begin{array}{l}\text { Semi- } \\
\text { annual } \\
\text { ampli- } \\
\text { tude } \\
{[\mathrm{mm}]}\end{array}$ & $\begin{array}{c}\text { Trend value } \\
\pm \text { error } \\
\text { [mm/year] }\end{array}$ \\
\hline & \multicolumn{4}{|c|}{ 16-year ZTD time series } & \multicolumn{4}{|c|}{ 18-year ZTD time series } \\
\hline MOPI & 2.256 & 49.92 & 8.48 & $-0.10 \pm 0.02$ & 2.257 & 49.14 & 8.67 & $-0.10 \pm 0.02$ \\
\hline ONSA & 2.391 & 46.63 & 8.36 & $0.12 \pm 0.02$ & 2.390 & 46.29 & 8.91 & $0.19 \pm 0.02$ \\
\hline PENC & 2.351 & 52.85 & 8.38 & $0.30 \pm 0.02$ & 2.350 & 52.10 & 8.74 & $0.45 \pm 0.02$ \\
\hline POTS & 2.378 & 49.15 & 8.59 & $0.23 \pm 0.02$ & 2.377 & 48.92 & 8.77 & $0.41 \pm 0.02$ \\
\hline RAMO & 2.153 & 13.72 & 8.49 & $0.33 \pm 0.01$ & 2.153 & 13.72 & 8.49 & $0.33 \pm 0.01$ \\
\hline REYK & 2.352 & 42.43 & 7.02 & $0.36 \pm 0.02$ & 2.352 & 42.45 & 6.59 & $0.18 \pm 0.02$ \\
\hline RIGA & 2.391 & 52.79 & 10.02 & $0.50 \pm 0.02$ & 2.390 & 52.72 & 10.39 & $0.50 \pm 0.02$ \\
\hline SFER & 2.423 & 24.23 & 4.58 & $0.19 \pm 0.02$ & 2.423 & 24.21 & 4.12 & $0.18 \pm 0.02$ \\
\hline SJDV & 2.313 & 45.73 & 6.45 & $0.13 \pm 0.02$ & & & & \\
\hline SODA & 2.283 & 50.99 & 10.57 & $0.40 \pm 0.02$ & & & & \\
\hline SOFI & 2.118 & 46.02 & 3.73 & $0.21 \pm 0.02$ & & & & \\
\hline SVTL & 2.368 & 53.56 & 11.35 & $0.21 \pm 0.02$ & 2.367 & 53.47 & 11.73 & $0.36 \pm 0.02$ \\
\hline TERS & 2.404 & 43.67 & 8.23 & $-0.27 \pm 0.02$ & & & & \\
\hline TORI & 2.354 & 63.34 & 5.94 & $-0.03 \pm 0.02$ & & & & \\
\hline TRO1 & 2.328 & 49.49 & 8.80 & $0.00 \pm 0.02$ & & & & \\
\hline UNPG & 2.342 & 46.92 & 1.49 & $-0.25 \pm 0.02$ & & & & \\
\hline VAAS & 2.367 & 51.25 & 9.48 & $0.42 \pm 0.02$ & & & & \\
\hline VIL0 & 2.249 & 47.87 & 8.80 & $0.21 \pm 0.02$ & & & & \\
\hline VILL & 2.255 & 28.91 & 0.78 & $-0.20 \pm 0.02$ & 2.255 & 29.40 & 1.08 & $-0.16 \pm 0.02$ \\
\hline VIS0 & 2.374 & 48.88 & 8.58 & $0.25 \pm 0.02$ & & & & \\
\hline WARE & 2.374 & 44.54 & 8.05 & $-0.19 \pm 0.02$ & 2.374 & 44.20 & 8.20 & $0.04 \pm 0.02$ \\
\hline WROC & 2.375 & 52.82 & 9.77 & $-0.14 \pm 0.02$ & & & & \\
\hline WSRT & 2.399 & 45.72 & 8.36 & $-0.09 \pm 0.02$ & & & & \\
\hline WTZR & 2.237 & 48.58 & 8.96 & $0.17 \pm 0.02$ & 2.236 & 48.17 & 9.00 & $0.34 \pm 0.02$ \\
\hline ZECK & 2.095 & 53.85 & 6.75 & $0.43 \pm 0.02$ & & & & \\
\hline ZIMM & 2.162 & 47.85 & 6.74 & $-0.04 \pm 0.02$ & 2.162 & 47.37 & 7.01 & $0.12 \pm 0.02$ \\
\hline
\end{tabular}

References

Bengtsson, L., S. Hagemann, and K.I. Hodges (2004), Can climate trends be calculated from reanalysis data? J. Geophys. Res. 109, D11, D1111, DOI: 10.1029/2004JD004536.

Bevis, M., S. Businger, T.A. Herring, C. Rocken, R.A. Anthes, and R.H. Ware (1992), GPS meteorology: Remote sensing of atmospheric water vapor us- 
ing the global positioning system, J. Geophys. Res. 97, D14, 15787-15801, DOI: 10.1029/92JD01517.

Bock, O., M.-N. Bouin, A. Walpersdorf, J.-P. Lafore, S. Janicot, F. Guichard, and A. Agusti-Panareda (2007), Comparison of ground-based GPS precipitable water vapour to independent observations and numerical weather prediction model reanalyses over Africa, Q. J. Roy. Meteor. Soc. 133, 629, 2011-2027, DOI: $10.1002 / q j .185$.

Bock, O., P. Willis, J. Wang, and C. Mears (2014), A high-quality, homogenized, global, long-term (1993-2008) DORIS precipitable water data set for climate monitoring and model verification, J. Geophys. Res. - Atmos. 119, 12, 7209-7230, DOI: 10.1002/2013JD021124.

Bruyninx, C. (2004), The EUREF Permanent Network: a multi-disciplinary network serving surveyors as well as scientists, GeoInformatics 7, 5, 32-35.

Byun, S.H., and Y.E. Bar-Server (2009), A new type of troposphere zenith path delay product of the international GNSS service, J. Geodesy 83, 3-4, 367-373, DOI: $10.1007 / \mathrm{s} 00190-008-0288-8$.

COST (2012), Memorandum of understanding for the implementation of a European Concerted Research Action, COST Action ES1206, Advanced Global Navigation Satellite Systems tropospheric products for monitoring severe weather events and climate (GNSS4SWEC), European Cooperation in Science and Technology.

Dach, R., U. Hugentobler, P. Fridez, and M. Meindl (eds.) (2007), Bernese GPS software version 5.0, User manual, Astronomical Institute, University of Bern, Bern, Switzerland.

Figurski, M., P. Kamiński, and A. Kenyeres (2009), Preliminary results of the complete EPN reprocessing computed by the MUT EPN Local Analysis Centre, Bull. Geod. Geomatics 1, 163-174.

Goosens, C., and A. Berger (1986), Annual and seasonal climatic variations over the northern hemisphere and Europe during the last century, Ann. Geophys. 4, 4, 385-400.

Guerova, G. (2013), Ground-based GNSS meteorology, Gfg ${ }^{2}$ Summer School, 2 July 2013, Potsdam, Germany.

Hagemann, S., L. Bengtsson, and G. Gendt (2003), On the determination of atmospheric water vapor from GPS measurements, J. Geophys. Res. 108, D21, 4678, DOI: 10.1029/2002JD003235.

Held, I.M., and B.J. Soden (2006), Robust responses of the hydrological cycle to global warming, J. Climate 19, 21, 5686-5699, DOI: 10.1175/JCLI3990.1.

Herring, T.A. (1992), Modeling atmospheric delays in the analysis of space geodetic data. In: J.C. de Munck, and T.A.T. Spoelstra (eds.), Proc. Symp. Refraction of Transatmospheric Signals in Geodesy, 19-22 May 1992, Hague, The Netherlands, 157-164. 
Hocke, K. (1998), Phase estimation with Lomb-Scargle periodogram method, Ann. Geophys. 16, 3, 356-358.

Jin, S., J.-U. Park, J.-H. Cho, and P.-H. Park (2007), Seasonal variability of GPSderived zenith tropospheric delay (1994-2006) and climate implications, J. Geophys. Res. 112, D9, D09110, DOI: 10.1029/2006JD007772.

Karmeshu, N. (2012), Trend detection in annual temperature and precipitation using Mann Kendall test - A case study to assess climate change on select states in the Northeastern United States, M.Sc. Thesis, University of Pennsylvania, Philadelphia, USA.

Kendall, M.G., and A. Stuart (1970), The Advanced Theory of Statistics. Vol. 2: Interference and Relationship, 3rd ed., Hafner, New York.

Lomb, N.R. (1976), Least-squares frequency analysis of unequally spaced data, Astrophys. Space Sci. 39, 2, 447-462, DOI: 10.1007/BF006483.

Mann, H.B. (1945), Nonparametric tests against trend, Econometrica 13, 3, 245-259, DOI: $10.2307 / 1907187$.

Marini, J.W. (1972), Correction of satellite tracking data for an arbitrary tropospheric profile, Radio Sci. 7, 2, 223-231, DOI: 10.1029/RS007i002p00223.

Mavromatis, T., and D. Stathis (2011), Response of the water balance in Greece to temperature and precipitation trends, Theor. Appl. Climatol. 104, 1-2, $13-$ 24, DOI: $10.1007 / \mathrm{s} 00704-010-0320-9$.

Niell, A.E. (1996), Global mapping functions for the atmospheric delay at radio wavelengths, J. Geophys. Res. 101, B2, 3227-3246, DOI: 10.1029/ 95JB03048.

Nilsson, T., and G. Elgered (2008), Long-term trends in the atmospheric water vapor content estimated from ground-based GPS data, J. Geophys. Res. 113, D19, D19101, DOI: 10.1029/2008JD010110.

Ning, T. (2012), GPS meteorology: with focus on climate application, Ph.D. Thesis, Department of Earth and Space Sciences, Chalmers University of Technology, Göteborg, Sweden.

Pacione, R., B. Pace, and G. Bianco (2014), An homogeneously reprocessed Zenith Total Delay long-term time series over Europe. In: EGU General Assembly, 27 April - 2 May 2014, Vienna, Austria, id. 2945.

Press, W.H., S.A. Teukolsky, W.T. Vetterling, and B.P. Flannery (1992), Numerical recipes in Fortran, 2nd ed., Cambridge University Press, Cambridge.

Ross, R.J., and W.P. Elliott (2001), Radiosonde-based northern hemisphere tropospheric water vapor trends, J. Climate 14, 7, 1602-1612, DOI: 10.1175/ 1520-0442(2001)014<1602:RBNHTW >2.0.CO;2.

Schüler, T. (2001), On ground-based GPS tropospheric delay estimation, Ph.D. Thesis, Universität der Bundeswehr, München, Germany, 364 pp.

Söhne, W., M. Figurski, and K. Szafranek (2010), Homogeneous Zenith Total Delay parameter estimation from European permanent GNSS sites, Bull. Geod. Geomatics 69, 1, 11-22. 
Steigenberger, P., M. Rothacher, R. Dietrich, M. Fritsche, A. Rülke, and S. Vey (2006), Reprocessing of a global GPS network, J. Geophys. Res. 111, B5, B05402, DOI: 10.1029/2005JB003747.

van Malderen, R., H. Brenot, E. Pottiaux, S. Beirle, C. Hermans, M. de Mazière, T. Wagner, H. de Backer, and C. Bruyninx (2014), A multi-site intercomparison of integrated water vapour observations for climate change analysis, Atmos. Meas. Tech. 7, 8, 2487-2512, DOI: 10.5194/amt-7-2487-2014.

Wang, J., and L. Zhang (2009), Climate applications of a global, 2-hourly atmospheric precipitable water dataset derived from IGS tropospheric products, J. Geodesy 83, 3-4, 209-217, DOI: 10.1007/s00190-008-0238-5.

Yong, W., Y. Binyun, W. Debao, and L. Yanping (2008), Zenith Tropospheric Delay from GPS monitoring climate change of Chinese Mainland. In: Int. Workshop on Education Technology and Training and on Geoscience and Remote Sensing, 21-22 December 2008, Shanghai, China, Vol. 1, 365-368, DOI: 10.1109/ETTandGRS.2008.43.

Received 20 January 2015

Received in revised form 9 April 2015

Accepted 10 April 2015 